\title{
Molecular Dynamics of Film Formation of Metal Tetrasulfonated Phthalocyanine and Poly Amidoamine Dendrimers
}

\author{
L. G. Silva, ${ }^{1}$ A. M. J. C. Neto, ${ }^{1}$ L. Gaffo, ${ }^{2}$ R. S. Borges, ${ }^{3}$ Teodorico C. Ramalho, ${ }^{4}$ \\ and Nélio Machado ${ }^{5}$ \\ ${ }^{1}$ Faculdade de Física-ICEN, Universidade Federal do Pará, C.P. 479, 66075-110 Belém, PA, Brazil \\ ${ }^{2}$ Centro de Engenharias e Ciências Exatas, Universidade Estadual do Oeste do Paraná, 85903-000 Toledo, PR, Brazil \\ ${ }^{3}$ Faculdade de Farmácia-ICS, Universidade Federal do Pará, C.P. 479, 66075-110 Belém, PA, Brazil \\ ${ }^{4}$ Departamento de Química, Campus Universitário-UFLA, Universidade Federal de Lavras, 37200-000 Lavras, MG, Brazil \\ ${ }^{5}$ Laboratory of Separation Processes and Applied Thermodynamic (TERM@), Faculty of Chemical Engineering-UFPA, \\ C.P. 8619 66075-900 Belém, PA, Brazil
}

Correspondence should be addressed to L. G. Silva; leandrogadelhasilva@hotmail.com

Received 6 November 2012; Accepted 29 January 2013

Academic Editor: Shuangxi Xing

Copyright (C) 2013 L. G. Silva et al. This is an open access article distributed under the Creative Commons Attribution License, which permits unrestricted use, distribution, and reproduction in any medium, provided the original work is properly cited.

\begin{abstract}
We performed molecular dynamics computer simulations to elucidate the behavior and properties of the metal tetrasulfonated phthalocyanine molecule and the poly(amidoamine) dendrimers in self-assembly depositions, respectively, on poly(allylamine hydrochloride) polymer and on film formed by metal tetrasulfonated phthalocyanine with poly(allylamine hydrochloride). Important physical properties of phthalocyanines were obtained such as the kinetic energy and temperature in situ. By the semiempirical model, we also obtained the UV-Vis absorption spectrum of the film formed by cobalt tetrasulfonated phthalocyanine deposited on poly(allylamine hydrochloride). We performed a study with poly(amidoamine) dendrimers on their deposition time on metal tetrasulfonated phthalocyanine, poly(allylamine hydrochloride) film, and we show the relationship of deposition time with the electrical charge and molecular mass of phthalocyanines. The deposition times of the dendrimers, as a function of their mass, were also elucidated.
\end{abstract}

\section{Introduction}

Studies about the formation of ultrathin organic film $[1,2]$ have intensified in recent years, since most devices are made with organic materials in the form known as layer by layer, in which two organic molecules are generally used, alternated, in the compound. In the assembly of these alternating layers, the layer by layer (LBL) self-assembly fabrication technique of nanostructured films [3-5] stands out.

In this work, nanostructured ultrathin films are formed based on the LBL technique by physical adsorption, based on the van der Waals interactions and electrostatic interactions between the polyelectrolytes of opposite charges. Computational simulations were performed using molecular dynamics (MD) [6-8] to increase the knowledge about the metal tetrasulfonated phthalocyanine (MTsPc) [915] and poly(amidoamine) (PAMAM)dendrimers [16-24] in the deposition process, respectively, on poly(allylamine hydrochloride) (PAH)polymers [25] and on the film formed by MTsPc with PAH (MTsPc-PAH).

Studies about the deposition of metal phthalocyanines [26-31] have intensified in recent years, due to the prospects of creating new materials [32] with applications in electronics, for being an organic semiconductor [33,34], optoelectronics [35], and in the developing of sensors with greater sensitivity and selectivity of gases and other products [36-40].

Mafatle and Nyokong [41] have used cobalt phthalocyanine to improve the sensitivity and stability of carbon electrodes for the detection of cresols, chlorophenol, and phenol. 
The detection of chlorine gas was performed using a newly developed gas sensor using copper phthalocyanine thin films. Miyata and coworkers [42] explain that there is an increase of the conductivity of copper phthalocyanine sensors with exposure to chlorine in gas phase.

The PAMAM dendrimer research areas have been diversifying over time. This organic macromolecule, which has a branched and highly symmetric molecular architecture, has revolutionary applications in the medical field as a possible carrier and distributor of specific drugs [43-45]. More recently, PAMAM dendrimers are being used in the development of new organic materials with applications in electronics and optoelectronics, such as the development of sensors, light emitting diodes and more efficient solar cells [46-49].

In the work of Zucolotto and coworkers [50], biosensors highly sensitive to detection of catechol were obtained through the formation of nanostructured films consisting of alternating layers of $\mathrm{Cl}$-catechol 1,2 dioxygenase and generation G4 PAMAM dendrimer.

We performed molecular dynamics simulations of the self-assembly of MTsPc molecule on the PAH polymer to elucidate its behavior and properties in this process. $M$ is the central atom of $\mathrm{MTsPc}$, which varies with the following metallic elements: copper $(\mathrm{Cu})$, cobalt $(\mathrm{Co})$, nickel $(\mathrm{Ni})$, iron $(\mathrm{Fe})$, and manganese $(\mathrm{Mn})$. The MTsPcs are anionic polyelectrolytes and the $\mathrm{PAH}$ is the cationic polyelectrolyte. We also obtained the ultraviolet-visible absorption spectrum (UV-Vis) using the semiempirical ZINDO/S method of the organic film CoTsPc-PAH.

Finally, we performed simulations of the self-assembly of PAMAM dendrimers generations GN on the MTsPc-PAH film, where $N=1,2,3,4$, and 5, showing the behavior of PAMAM dendrimers in this process. These dendrimers are cationic polyelectrolytes.

We obtained the kinetic energy, and temperature in situ, and calculated the molar entropy variation and the ratio between the kinetic energy and temperature in situ of MTsPcs. We also show the deposition time of MTsPcs on $\mathrm{PAH}$, as well as the deposition time of PAMAM dendrimers on the MTsPc-PAH film.

\section{Theory}

Molecular dynamics methods were used to obtain information about the dynamic behavior of MTsPcs and PAMAM dendrimers in time dependence. The Hamiltonian of the system is given by the following equation:

$$
H\left(\mathbf{r}_{1}, \ldots, \mathbf{r}_{n}, \mathbf{P}_{1}, \ldots, \mathbf{P}_{n}\right)=\sum_{i=1}^{n} \frac{P_{i}^{2}}{2 m_{i}}+U\left(\mathbf{r}_{1}, \ldots, \mathbf{r}_{n}\right)
$$

where $\mathbf{r}, \mathbf{P}$, and $m$ are the position, momentum, and mass of the particle, respectively, and $U$ is the potential energy of the particle.
We defined some physical properties calculated in this work; for example, the molar entropy variation $(\Delta S)$ of this system is given by

$$
\Delta S=\frac{\Delta E_{\mathrm{TOT}}}{T_{\text {insitu }}}
$$

where $T_{\text {in situ }}$ is the temperature in situ and $E_{\mathrm{TOT}}$ is the total energy.

We determined the constant proportionality $K_{p}$ of the molecules given by

$$
\frac{E_{\mathrm{KIN}}}{T_{\text {in situ }}}=K_{p} \text {, }
$$

where $E_{\mathrm{KIN}}$ is the kinetic energy of system.

\section{Methodology}

We performed classical molecular dynamics simulations to understand the deposition dynamics of the MTsPc $(M=\mathrm{Cu}$, $\mathrm{Co}, \mathrm{Ni}, \mathrm{Fe}$, and $\mathrm{Mn}$ ) on the $\mathrm{PAH}$ polymer and PAMAM dendrimers generation $\mathrm{GN}(N=1,2,3,4$, and 5), on the MTsPc-PAH film. The deposition occurs mainly by van der Waals force and electrostatic force between the polyelectrolytes of opposite charge.

For the optimization of the molecular architecture of all the molecules, we used the Polak-Ribiere algorithm (conjugate gradient) with RMS gradient $0.1 \mathrm{kcal} /(\mathrm{mol}$ Angstrom). In this paper, we worked with the $\mathrm{MM}+$ force field. The simulations were performed with a step of 1 femtosecond in vacuum.

Optimization energy values of phthalocyanines metal atoms are $\mathrm{Mn}:-152.4 \mathrm{kcal} / \mathrm{mol}$, Fe: $-161.9 \mathrm{kcal} / \mathrm{mol}$, Co: $-151.5 \mathrm{kcal} / \mathrm{mol}, \mathrm{Cu}:-131.6 \mathrm{kcal} / \mathrm{mol}, \mathrm{Ni}:-138.5 \mathrm{kcal} / \mathrm{mol}$, and PAH: $-1611.1 \mathrm{kcal} / \mathrm{mol}$. Otherwise, the PAMAM dendrimers have optimization energy values of G1: $-16.4 \mathrm{kcal} / \mathrm{mol}, \mathrm{G} 2$ : $-58.4 \mathrm{kcal} / \mathrm{mol}, \mathrm{G} 3:-134.4 \mathrm{kcal} / \mathrm{mol}, \mathrm{G} 4:-237.6 \mathrm{kcal} / \mathrm{mol}$, and G5: $-327.4 \mathrm{kcal} / \mathrm{mol}$.

3.1. MTsPc-PAH System. After the optimization of the molecules, we put each MTsPc, relaxed, at a distance of about $17 \AA$ from $\mathrm{PAH}$, fixed. We set the initial temperature of the system as $300 \mathrm{~K}$, and the total simulation time was $200 \mathrm{ps,}$ which is enough time for system analysis. We obtained the theoretical UV-Vis absorption spectrum of the nanostructured film formed by the CoTsPc-PAH, by the semi-empirical ZINDO/S method.

3.2. GN PAMAM-MTsPc-PAH System. After the optimizations of the PAMAM dendrimer, each generation, relaxed, was separated from the core, by a distance of $23 \AA$ from the central atom of the film MTsPc-PAH, fixed. The initial temperature of system was $300 \mathrm{~K}$, and total simulation time was $100 \mathrm{ps}$, which is enough time to equilibrate the system.

All simulations were carried out applying Launois et al. [51] and Neto [52-56] methodology using Hyperchem 7.5 software [57]. 


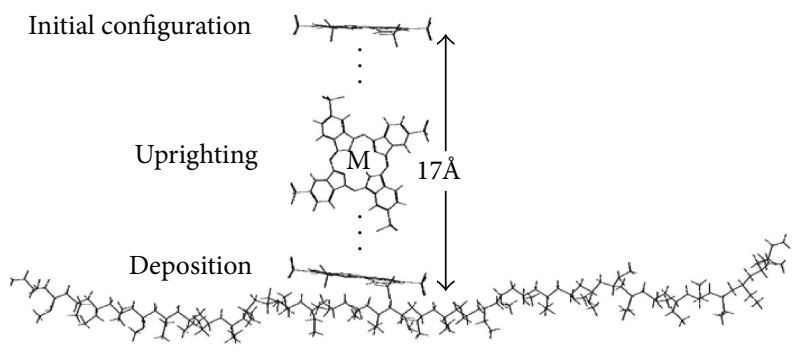

FIgUre 1: Initial MTsPc-PAH system.

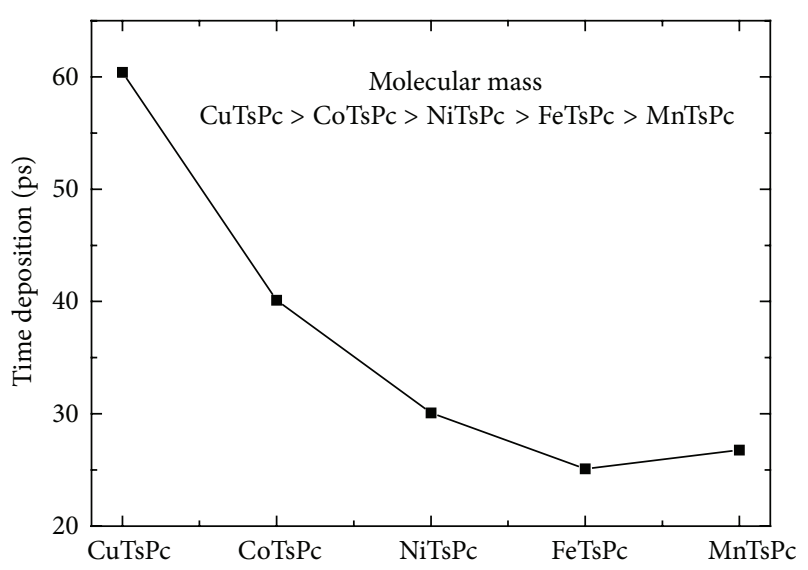

FIgURe 2: Deposition time (ps) of MTsPcs versus molecular mass.

\section{Results and Discussion}

Figure 1 displays the behavior of the MTsPc, where $M=\mathrm{Cu}$, $\mathrm{Co}, \mathrm{Ni}, \mathrm{Fe}$, and $\mathrm{Mn}$, in the deposition process on PAH. From the beginning of the simulation, the MTsPcs begin to move toward PAH due to van der Waals forces and electrostatic forces. We observed an MTsPcs pattern behavior, which occurred between 10 ps and 15 ps of simulation. During this interval, an uprighting of MTsPcs preceding the deposition was verified. This uprighting is due to electrostatic attraction between the sulfonate groups of MTsPcs and the amines of PAH. After the uprighting, the deposition of the MTsPcs occurs. In Figure 2, we show the MTsPc deposition time, which is organized in decreasing order of the atomic mass of the central metal element. It is observed that the CuTsPc, which has the highest molecular mass, takes a longer time to deposit, about $60.40 \mathrm{ps}$, and the FeTsPc takes a shorter time, about $25.11 \mathrm{ps}$. It can be seen that the deposition time for MTsPcs tends to decrease with the lower molecular mass. However, in Figure 2, the MnTsPc deposition time was longer than the deposition time of FeTsPc, despite having the lower molecular mass. We can understand this behavior by looking for an electrical charge of the MTsPcs. The FeTsPc region has a greater negative charge than the MnTsPc, which explains their deposition in less time.

Figure 3 illustrates the $E_{\mathrm{KIN}}$ of MTsPcs versus time. The $E_{\mathrm{KIN}}$ curves grow over time, due to increased molecular agitation caused by interaction with $\mathrm{PAH}$. The MnTsPc reached the highest value in $E_{\mathrm{KIN}}$, about $716 \mathrm{kcal} / \mathrm{mol}$ at

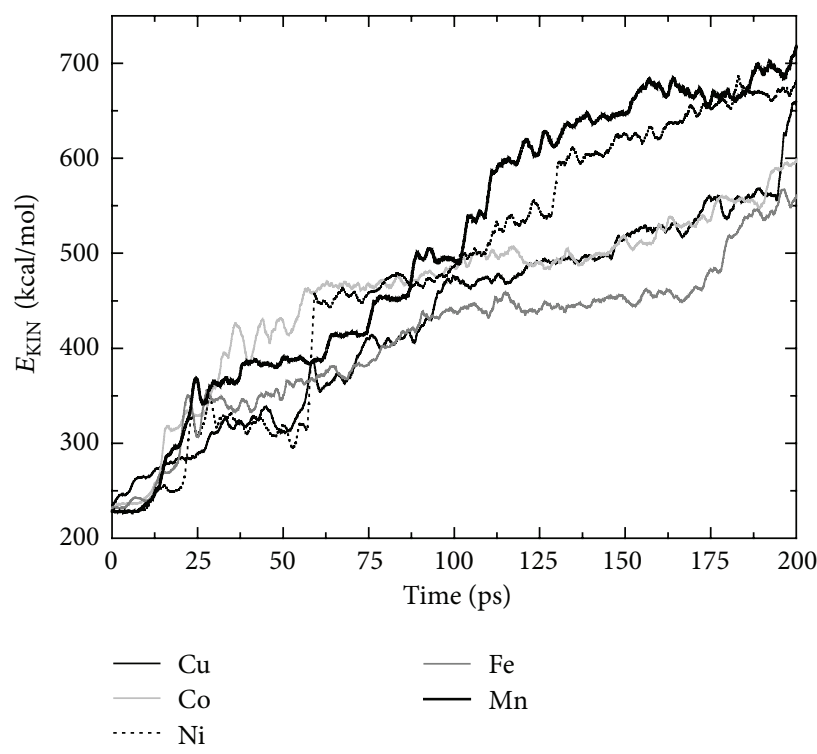

FIGURE 3: Kinetic energy ( $\mathrm{kcal} / \mathrm{mol})$ of MTsPcs versus simulation time (ps).

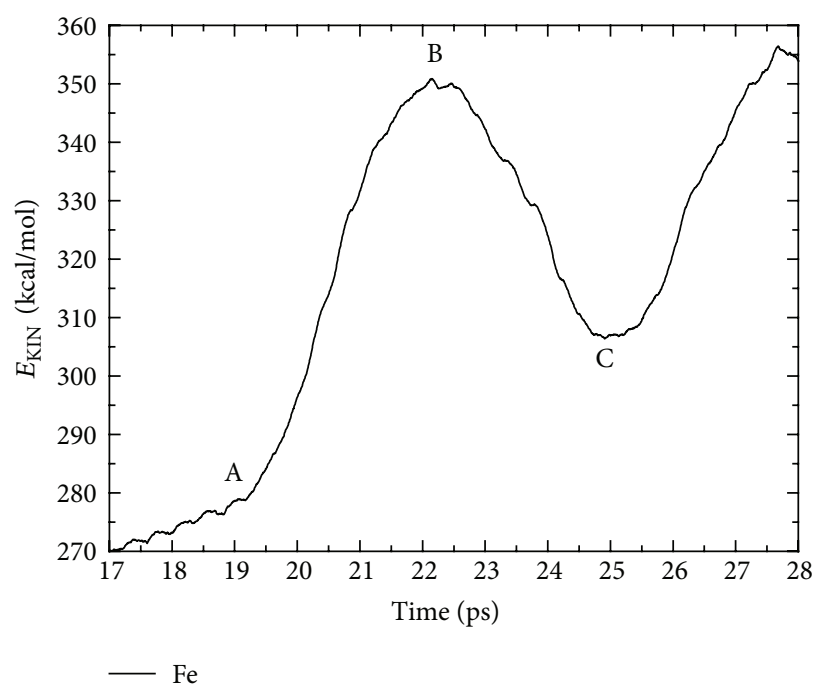

FIGURE 4: Kinetic energy (kcal/mol) at FeTsPcs deposition time (ps).

200 ps. At the deposition time, there were also peaks in $E_{\mathrm{KIN}}$ which indicate the MTsPcs deposition.

These peaks are detailed in Figure 4 about FeTsPc. At point $A$, the deposition of FeTsPcs effectively starts. The FeTsPc is attracted by $\mathrm{PAH}$ due to van der Waals and electrostatic interaction forces. There is an increase of $E_{\mathrm{KIN}}$ until point $B$. For point $B$, the intermolecular forces become repulsive due to the great approximation between these polyelectrolytes. The interpolation of the electron clouds between these polyelectrolytes also led to a slowdown of the FeTsPc limiting the approximation with $\mathrm{PAH}$. At point $C$, there is the closest approach of FeTsPcs with the PAH. The time of point $C$ is taken as the deposition time of the FeTsPc on $\mathrm{PAH}$ in this case, 24.90 ps. From this point the 


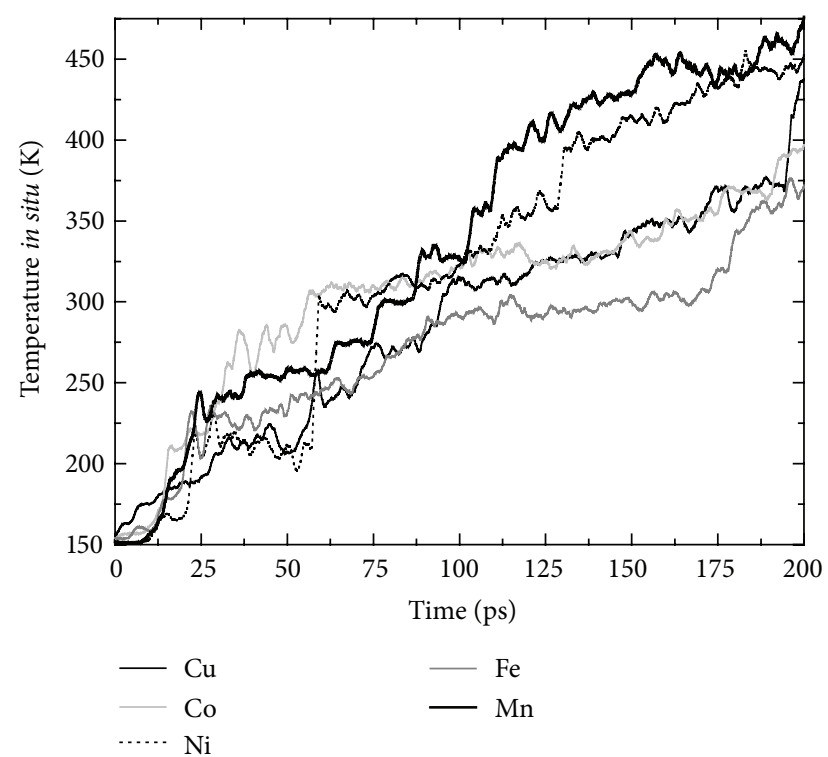

Figure 5: Temperature in situ (K) versus simulation time (ps).

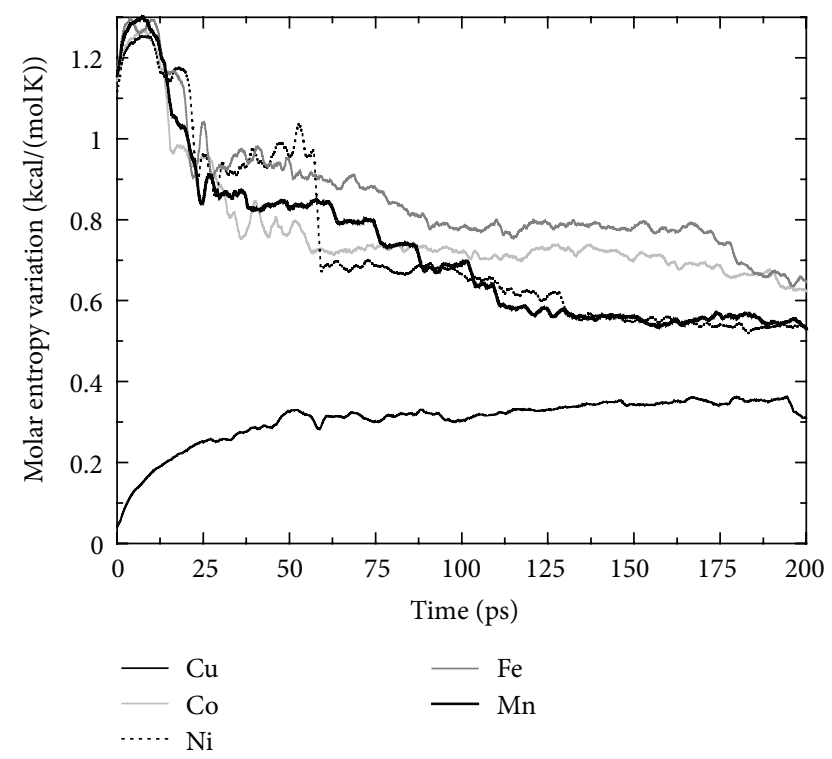

Figure 6: Molar entropy variation $(\mathrm{kcal} /(\mathrm{mol} \mathrm{K}))$ of MTsPcs versus simulation time (ps).

intermolecular forces become balanced, and FeTsPcs tend to stabilize on the PAH. All other phthalocyanines had these qualitatively similar behaviors.

Figure 5 illustrates the $T_{\text {in situ }}$ of the MTsPcs versus time. The $T_{\text {insitu }}$ curve grows in time function, due to increasing atomic agitation. Analyzing the total simulation time, we find that MnTsPc reaches a maximum value of $473 \mathrm{~K}$ close to 200 ps.

Figure 6 shows the molar entropy variation as a function of simulation time. At the beginning of the simulation, all MTsPcs have grown $\Delta S$; however, at about $7 \mathrm{ps}$, a decrease in $\Delta S$ occurs in the MnTsPc, FeTsPc, CoTsPc, and NiTsPc. They tend to stabilize on the substrate. It can be observed that the

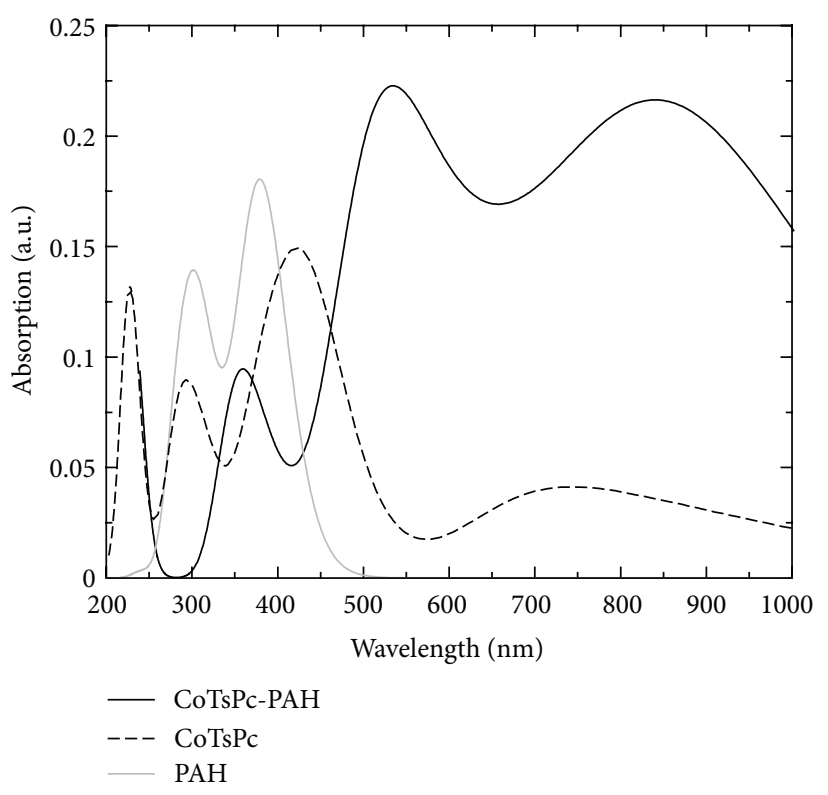

Figure 7: Absorption (a.u.) of CoTsPc, CoTsPc-PAH, and PAH versus wavelength $(\mathrm{nm})$.

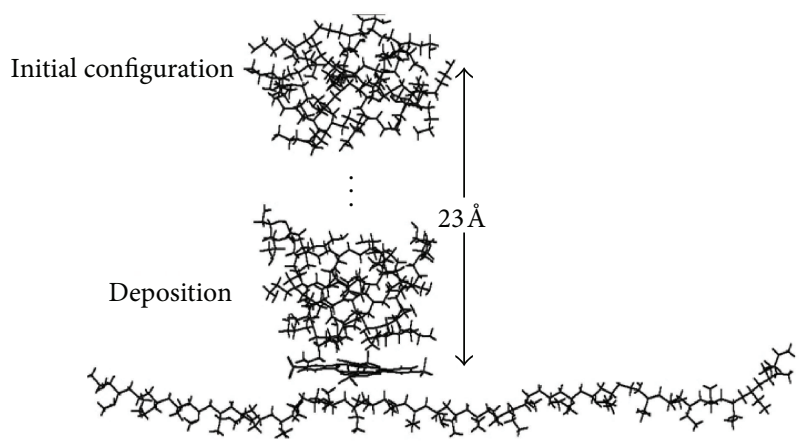

Figure 8: GN PAMAM -MTsPc-PAH system.

$\Delta S$ of the CuTsPc takes a longer time to start decreasing. At 200 ps of simulation, the CuTsPc has the lowest $\Delta S$ values, which shows its higher stability. The highest value of $\Delta S$ occurs with MnTsPc and FeTsPc at 11.45 ps, whose value was $1.30 \mathrm{kcal} / \mathrm{mol} \mathrm{K}$.

The ratio $E_{\mathrm{KIN}} / T_{\text {in situ }}$ of MTsPcs has a constant value equal to 1.50828 .

We have shown, in Figure 7, the UV-Vis theoretical absorption spectrum of the CoTsPc, $\mathrm{PAH}$, and the resulting film. Note that the resultant absorption spectrum is formed by contribution of the absorption spectra of CoTsPc and $\mathrm{PAH}$. We also note that at the wavelengths between $268 \mathrm{~nm}$, and $297 \mathrm{~nm}$ the absorption of the film is equal to zero; that is, there were no electronic jumps. It could be inferred that the presence of CoTsPc restricts the electronic jump of PAH which in turn also limits the electronic jump of CoTsPc.

Figure 8 illustrates the behavior of the GN PAMAM dendrimers in the deposition process on MTsPc-PAH films. From the beginning of the simulation, the PAMAM begins to 


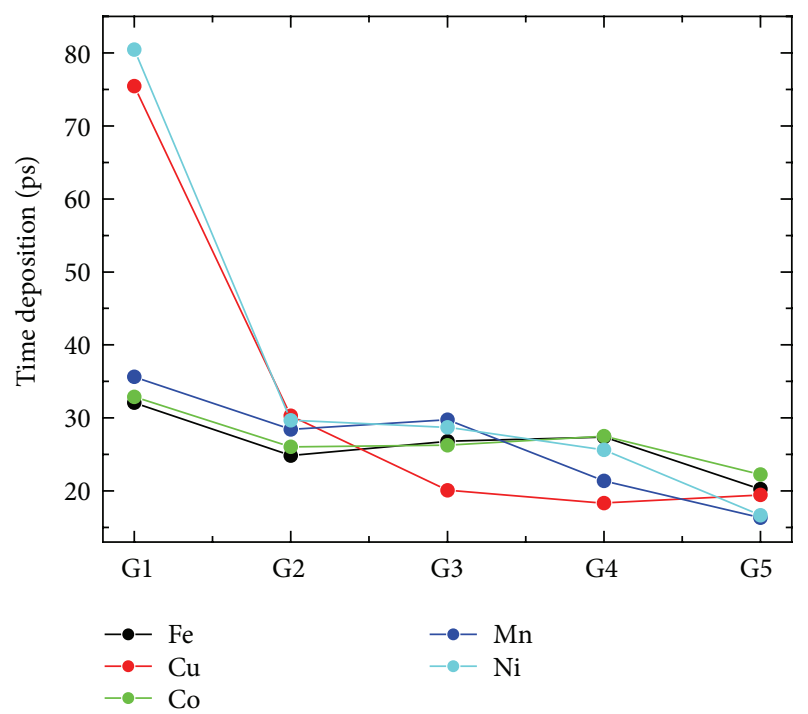

FIGURE 9: Deposition time of GN PAMAM on MTsPc-PAH film versus generation.

move toward MTsPc-PAH due to van der Waals forces and electrostatic forces between the polyelectrolytes. Naturally, the dendrimers are deposited exactly on the MTsPcs films because they are polyelectrolytes with different charges. We found that PAMAM dendrimers are flattened due to the intensity of intermolecular forces. Figure 9 displays the deposition time of GN generations of PAMAM dendrimers on MTsPcs-PAH, where $M=\mathrm{Fe}, \mathrm{Cu}, \mathrm{Co}, \mathrm{Mn}$, and Ni. The system that took more time to form was the NiTsPc-G1 PAMAMPAH, where the G1 PAMAM was deposited at an interval of about 84.5 ps. This result is satisfactory, as the G1 PAMAM has less hydrogen, which has partial positive charges, and the NiTsPc has less negative charge compared with other phthalocyanines. The fastest formed system was the MnTsPcG5 PAMAM-PAH, at an interval of about $16.3 \mathrm{ps}$, which is satisfactory, since the G5 PAMAM has more partial positive charges due to hydrogen. The PAMAM generation deposition times tend to decrease with increasing generations, which can be understood by the systematic increase of partial positive charges in these dendrimers.

\section{Conclusions}

We found that the CuTsPc takes a longer time to deposit, about $60.40 \mathrm{ps}$, and that $\mathrm{FeTsPc}$ spends a shorter time, about 25.11 ps. Both the molecular mass and the electronic charge have an influence on the deposition of MTsPcs. The deposition time for MTsPcs tends to decrease with reduction of molecular mass. The molecular mass explains the longer deposition time of the phthalocyanine CuTsPc since this has a higher molecular mass. The charge explains the FeTsPc shorter deposition time, since this phthalocyanine has the more negative charge in this work.
The kinetic energy grows with the increase in simulation time, and the in situ temperature and the molar entropy variation decreases with time, since the MTsPcs seek equilibrium as they are deposited on the PAH.

The $E_{\mathrm{KIN}} / T_{\text {in situ }}$ ratio of the MTsPcs has a constant value equal to 1.50828 . We found that the CoTsPc-PAH films have a wavelength range in which the electronic jumps do not occur. This is because this phthalocyanine prevents electronic jumps of the PAH and vice versa. The G1 PAMAM was deposited more slowly on NiTsPc-PAH film at an interval of $84.5 \mathrm{ps}$, and G5 PAMAM was deposited more quickly on MnTsPc-PAH film at an interval of $16.3 \mathrm{ps}$. The deposition time of PAMAM dendrimers on the MTsPc-PAH tends to decrease as their generations increase.

\section{Disclosure}

L. G. Silva attests to the fact that all authors listed on the title page have read the paper, he attest to the validity and legitimacy of the data and its interpretation, and he agrees to its submission to the Journal of Nanomaterials. The authors are submitting the manuscript as an original paper. The authors listed do not have any financial relation with the commercial identity mentioned in this paper, and there is no conflict of interests.

\section{Acknowledgments}

A. M. J. C. Neto thanks the support given by PIBIC-CNPQ, PROPESP/UFPA, and Reitoria/UFPA. L. G. Silva thanks SIBOP-PROEX/UFPA and PROINT 2012-2013/UFPA.

\section{References}

[1] S. R. Puniredd and M. P. Srinivasan, "Covalent molecular assembly of multilayer dendrimer ultrathin films in supercritical medium," Journal of Colloid and Interface Science, vol. 306, no. 1, pp. 118-127, 2007.

[2] S. R. Forrest, "Ultrathin organic films grown by organic molecular beam deposition and related techniques," Chemical Reviews, vol. 97, no. 6, pp. 1793-1896, 1997.

[3] J. Wang, X. Jia, H. Zhong et al., "Self-assembled multilayer films based on dendrimers with covalent interlayer linkage," Chemistry of Materials, vol. 14, no. 7, pp. 2854-2858, 2002.

[4] J. Wang, J. Chen, X. Jia, W. Cao, and M. Li, "Self-assembly ultrathin films based on dendrimers," Chemical Communications, no. 6, pp. 511-512, 2000.

[5] J. Yu-Hang, L. Li-Wei, Y. Kai, X. Wen-De, and G. Hong-Jun, "Self-assembly and growth of manganese phthalocyanine on an $\mathrm{Au}(111)$ surface," Chinese Physics B, vol. 20, no. 9, Article ID 096401, 2011.

[6] F. M. S. S. Fernandes, "Simulação computacional, o método da dinâmica molecular," Ciência, vol. 20, pp. 10-15, 1988.

[7] R. Sanjeewa and S. Weerasinghe, "Study of aggregate formation of caffeine in water by molecular dynamics simulation," Computational and Theoretical Chemistry, vol. 966, pp. 140-148, 2011.

[8] I. Kurisaki and T. Takahashi, "Assessment of dynamic properties of water around a monovalent ion: a classical molecular dynamics simulation study," Computational and Theoretical Chemistry, vol. 966, pp. 26-30, 2011. 
[9] X. Luo, L. Xu, B. Xu, and F. Li, "Electrodeposition of zinc oxide/tetrasulfonated copper phthalocyanine hybrid thin film for dye-sensitized solar cell application," Applied Surface Science, vol. 257, no. 15, pp. 6908-6911, 2011.

[10] V. Zucolotto, M. Ferreira, M. R. Cordeiro et al., "Unusual interactions binding iron tetrasulfonated phthalocyanine and poly(allylamine hydrochloride) in layer-by-layer films," Journal of Physical Chemistry B, vol. 107, no. 16, pp. 3733-3737, 2003.

[11] V. Zucolotto, M. Ferreira, M. R. Cordeiro, C. J. L. Constantino, W. C. Moreira, and O. N. Oliveira, "Electroactive layer-by-layer films of iron tetrasulfonated phthalocyanine," Synthetic Metals, vol. 137, no. 1-3, pp. 945-946, 2003.

[12] S. Samanta, A. Singh, A. K. Debnath, D. K. Aswal, S. K. Gupta, and J. V. Yakhmi, "Temperature dependent current-voltage characteristics of iron-phthalocyanine thin films," Journal of Nanoscience and Nanotechnology, vol. 9, no. 9, pp. 5262-5267, 2009.

[13] J. R. Silva, J. B. Brito, S. T. Tanimoto, and N. C. Souza, "Morphological structure characterization of $\mathrm{PAH} / \mathrm{NiTsPc}$ multilayer nanostructured films," Materials Sciences and Applications, vol. 2, pp. 1661-1666, 2011.

[14] B. Marí, M. M. Moya, K. C. Singh et al., "Characterization of electrodeposited zinc oxide/tetrasulphonatedcopper phthalocyanines $(\mathrm{ZnO} / \mathrm{Ts}-\mathrm{CuPc})$ hybrid films and their photoelectrochemical properties," Journal of Electroanalytical Chemistry, vol. 653, no. 1-2, pp. 86-92, 2011.

[15] Y. Karakuş, M. Okutan, A. Kösemen, S. E. San, Z. Alpaslan, and A. Demir, "Electrical properties of Zn-Phthalocyanine and poly(3-hexylthiophene) doped nematic liquid crystal," Journal of Nanomaterials, vol. 2011, Article ID 729085, 5 pages, 2011.

[16] G. Milczarek, "Self-doped polyaniline films prepared by electropolymerization in the presence of sulfonated nickel phthalocyanine," Thin Solid Films, vol. 517, no. 21, pp. 6100-6104, 2009.

[17] L. Qian and X. Yang, "Dendrimers as "controllers" for modulation of electrodeposited silver nanostructures," Colloids and Surfaces A, vol. 317, no. 1-3, pp. 528-534, 2008.

[18] D. Astruc, E. Boisselier, and C. Ornelas, "Dendrimers designed for functions: from physical, photophysical, and supramolecular properties to applications in sensing, catalysis, molecular electronics, photonics, and nanomedicine," Chemical Reviews, vol. 110, no. 4, pp. 1857-1959, 2010.

[19] T. R. Hendricks, E. E. Dams, S. T. Wensing, and I. Lee, "Effects of catalyst introduction methods using PAMAM dendrimers on selective electroless nickel deposition on polyelectrolyte multilayers," Langmuir, vol. 23, no. 13, pp. 7404-7410, 2007.

[20] J. Yuan, D. Han, Y. Zhang et al., "Electrostatic assembly of polyaniline and platinum-poly(amidoamine) dendrimers hybrid nanocomposite multilayer, and its electrocatalysis towards $\mathrm{CO}$ and $\mathrm{O}_{2}$," Journal of Electroanalytical Chemistry, vol. 599, no. 1, pp. 127-135, 2007.

[21] A. J. Khopade and F. Caruso, "Electrostatically assembled polyelectrolyte/dendrimer multilayer films as ultrathin nanoreservoirs," Nano Letters, vol. 2, no. 4, pp. 415-418, 2002.

[22] A. J. Khopade and F. Caruso, "Investigation of the factors influencing the formation of dendrimer/polyanion multilayer films," Langmuir, vol. 18, no. 20, pp. 7669-7676, 2002.

[23] S. Tomita, K. Sato, and J. I. Anzai, "Preparation of dendrimerloaded microcapsules by a layer-by-layer deposition of polyelectrolytes," Materials Science and Engineering C, vol. 29, no. 6, pp. 2024-2028, 2009.

[24] Z. Liu, X. Zhang, Y. Zhang, and J. Jiang, “Theoretical investigation of the molecular, electronic structures and vibrational spectra of a series of first transition metal phthalocyanines," Spectrochimica Acta A, vol. 67, no. 5, pp. 1232-1246, 2007.

[25] N. C. de Souza, V. Zucolotto, J. R. Silva et al., "Morphology characterization of layer-by-layer films from PAH/MA-coDR13: the role of film thickness," Journal of Colloid and Interface Science, vol. 285, no. 2, pp. 544-550, 2005.

[26] N. Sato, H. Yoshida, and K. Tsutsumi, "Unoccupied electronic states in phthalocyanine thin films studied by inverse photoemission spectroscopy," Synthetic Metals, vol. 133-134, pp. 673674, 2003.

[27] M. S. Liao and S. Scheiner, "Electronic structure and bonding in metal phthalocyanines, metal = Fe, Co, Ni, Cu, Zn, Mg," Journal of Chemical Physics, vol. 114, no. 22, pp. 9780-9791, 2001.

[28] A. Shaabani, R. Maleki-Moghaddam, A. Maleki, and A. H. Rezayan, "Microwave assisted synthesis of metal-free phthalocyanine and metallophthalocyanines," Dyes and Pigments, vol. 74, no. 2, pp. 279-282, 2007.

[29] H. Tajima, N. Hanasaki, M. Matsuda, F. Sakai, T. Naito, and T. Inabe, "Magnetoresistance study on TPP $\left[M(\mathrm{Pc})(\mathrm{CN})_{2}\right]_{2}$ $\left(\mathrm{M}=\mathrm{Fe}, \mathrm{Co}, \mathrm{Fe}_{0.30} \mathrm{Co}_{0.70}\right)$ salts," Journal of Solid State Chemistry, vol. 168, no. 2, pp. 509-513, 2002.

[30] M. Haifang, S. Yipeng, L. Hongwu et al., "Molecular deposition film of porphyrin and phthalocyanine bearing oppositely charged substituents," Science in China B, vol. 41, no. 5, pp. 449454, 1998.

[31] H. Yoshida, K. Tsutsumi, and N. Sato, "Unoccupied electronic states of 3d-transition metal phthalocyanines ( $M P c: M=M n$, $\mathrm{Fe}, \mathrm{Co}, \mathrm{Ni}, \mathrm{Cu}$ and $\mathrm{Zn}$ ) studied by inverse photoemission spectroscopy," Journal of Electron Spectroscopy and Related Phenomena, vol. 121, no. 1-3, pp. 83-91, 2001.

[32] S. Heutz, C. Mitra, W. Wu et al., "Molecular thin films: a new type of magnetic switch," Advanced Materials, vol. 19, pp. 36183622, 2007.

[33] M. Bora, D. Schut, and M. A. Baldo, "Combinatorial detection of volatile organic compounds using metal-phthalocyanine field effect transistors," Analytical Chemistry, vol. 79, no. 9, pp. 32983303, 2007.

[34] N. B. Chaurel, T. Basova, A. K. Ray, A. G. Gürek, and V. Ahsen, "Memory effects in thin film organic transistor characteristics," Journal of Physics D, vol. 42, no. 12, Article ID 125103, 2009.

[35] I. Bruder, J. Schöneboom, R. Dinnebier et al., "What determines the performance of metal phthalocyanines ( $M P c, M=Z n$, $\mathrm{Cu}, \mathrm{Ni}, \mathrm{Fe}$ ) in organic heterojunction solar cells? A combined experimental and theoretical investigation," Organic Electronics, vol. 11, pp. 377-387, 2010.

[36] F. I. Bohrer, C. N. Colesniuc, J. Park et al., "Comparative gas sensing in cobalt, nickel, copper, zinc, and metal-free phthalocyanine chemiresistors," Journal of the American Chemical Society, vol. 131, no. 2, pp. 478-485, 2009.

[37] J. Janata and M. Josowicz, "Organic semiconductors in potentiometric gas sensors," Journal of Solid State Electrochemistry, vol. 13, no. 1, pp. 41-49, 2009.

[38] Z. Z. Öztürk, N. Kılınça, D. Atillac, A. G. Gürekc, and V. Ahsen, "Recent studies chemical sensors based on phthalocyanines," Journal of Porphyrins and Phthalocyanines, vol. 13, pp. 1179-1187, 2009.

[39] L. M. P. C. Centurion, W. C. Moreira, and V. Zucolotto, "Tailoring molecular architectures with cobalt tetrasulfonated phthalocianine: immobilization in Layer by Layer films and sensing applications," Journal of Nanoscience and Nanotechnology, vol. 12, pp. 2399-2405, 2012. 
[40] E. Strelcov and A. Kolmakov, "Copper phthalocyanine quasi-1 nanostructures: growth morphologies and gas sensing properties," Journal of Nanoscience and Nanotechnology, vol. 8, no. 1, pp. 212-221, 2008.

[41] T. Mafatle and T. Nyokong, "Use of cobalt(II) phthalocyanine to improve the sensitivity and stability of glassy carbon electrodes for the detection of cresols, chlorophenols and phenol," Analytica Chimica Acta, vol. 354, no. 1-3, pp. 307-314, 1997.

[42] T. Miyata, S. Kawaguchi, M. Ishii, and T. Minami, "High sensitivity chlorine gas sensors using $\mathrm{Cu}$-phthalocyanine thin films," Thin Solid Films, vol. 425, no. 1-2, pp. 255-259, 2003.

[43] R. Esfand and D. A. Tomalia, "Poly(amidoamine) (PAMAM) dendrimers: from biomimicry to drug delivery and biomedical applications," Drug Discovery Today, vol. 6, no. 8, pp. 427-436, 2001.

[44] J. Hu, Y. Su, H. Zhang, T. Xu, and Y. Cheng, "Design of interiorfunctionalized fully acetylated dendrimers for anticancer drug delivery," Biomaterials, vol. 32, pp. 9950-9959, 2011.

[45] L. J. Twyman, A. E. Beezer, R. Esfand, M. J. Hardy, and J. C. Mitchell, "The synthesis of water soluble dendrimers, and their application as possible drug delivery systems," Tetrahedron Letters, vol. 40, no. 9, pp. 1743-1746, 1999.

[46] T. D. Anthopoulos, J. P. J. Markham, E. B. Namdas, I. D. W. Samuel, S. C. Lo, and P. L. Burn, "Highly efficient singlelayer dendrimer light-emitting diodes with balanced charge transport," Applied Physics Letters, vol. 82, no. 26, pp. 48244826, 2003.

[47] A. W. Freeman, S. C. Koene, P. R. L. Malenfant, M. E. Thompson, and J. M. J. Fréchet, "Dendrimer-containing light-emitting diodes: toward site-isolation of chromophores," Journal of the American Chemical Society, vol. 122, no. 49, pp. 12385-12386, 2000.

[48] M. Halim, J. N. G. Pillow, I. D. W. Samuel, and P. L. Burn, "Effect of dendrimer generation on LED efficiency," Synthetic Metals, vol. 102, no. 1-3, pp. 922-923, 1999.

[49] S. Ogasawara, A. Ikeda, and J. I. Kikuchi, "Positive dendritic effect in DNA/porphyrin composite photocurrent generators containing dendrimers as the stationary phase," Chemistry of Materials, vol. 18, no. 25, pp. 5982-5987, 2006.

[50] V. Zucolotto, A. P. A. Pinto, T. Tumolo et al., "Catechol biosensing using a nanostructured layer-by-layer film containing $\mathrm{Cl}$ catechol 1,2-dioxygenase," Biosensors and Bioelectronics, vol. 21, no. 7, pp. 1320-1326, 2006.

[51] P. Launois, A. Marucci, B. Vigolo, P. Bernier, A. Derré, and P. Poulin, "Structural characterization of nanotube fibers by x-ray scattering," Journal of Nanoscience and Nanotechnology, vol. 1, no. 2, pp. 125-128, 2001.

[52] A. M. J. C. Neto, "Carbon nanotube and iron circle as molecular motor controlled by visible light," Journal of Computational and Theoretical Nanoscience, vol. 4, no. 4, pp. 745-748, 2007.

[53] A. M. J. C. Neto, "Carbon nanotube and ordinary nanowire track as molecular motor," Journal of Computational and Theoretical Nanoscience, vol. 4, no. 3, pp. 611-613, 2007.

[54] A. M. J. C. Neto, "Carbon nanotube and iron circle as molecular motor under temperature effect," Journal of Computational and Theoretical Nanoscience, vol. 5, no. 3, pp. 314-316, 2008.

[55] A. M. J. C. Neto and G. V. D. Mota, "Carbon nanotube and ordinary nanowire track as molecular motor under temperature effect," Journal of Computational and Theoretical Nanoscience, vol. 5, no. 3, pp. 311-313, 2008.
[56] A. M. D. J. Neto, "Molecular carbon nanotubes as molecular gun under temperature effect," Journal of Computational and Theoretical Nanoscience, vol. 5, no. 4, pp. 605-607, 2008.

[57] HYPERCHEM, Hypercube, Inc., $1115 \mathrm{NW}$ 4th Street, Gainesville, Florida 32601, http://www.hyper.com/. 

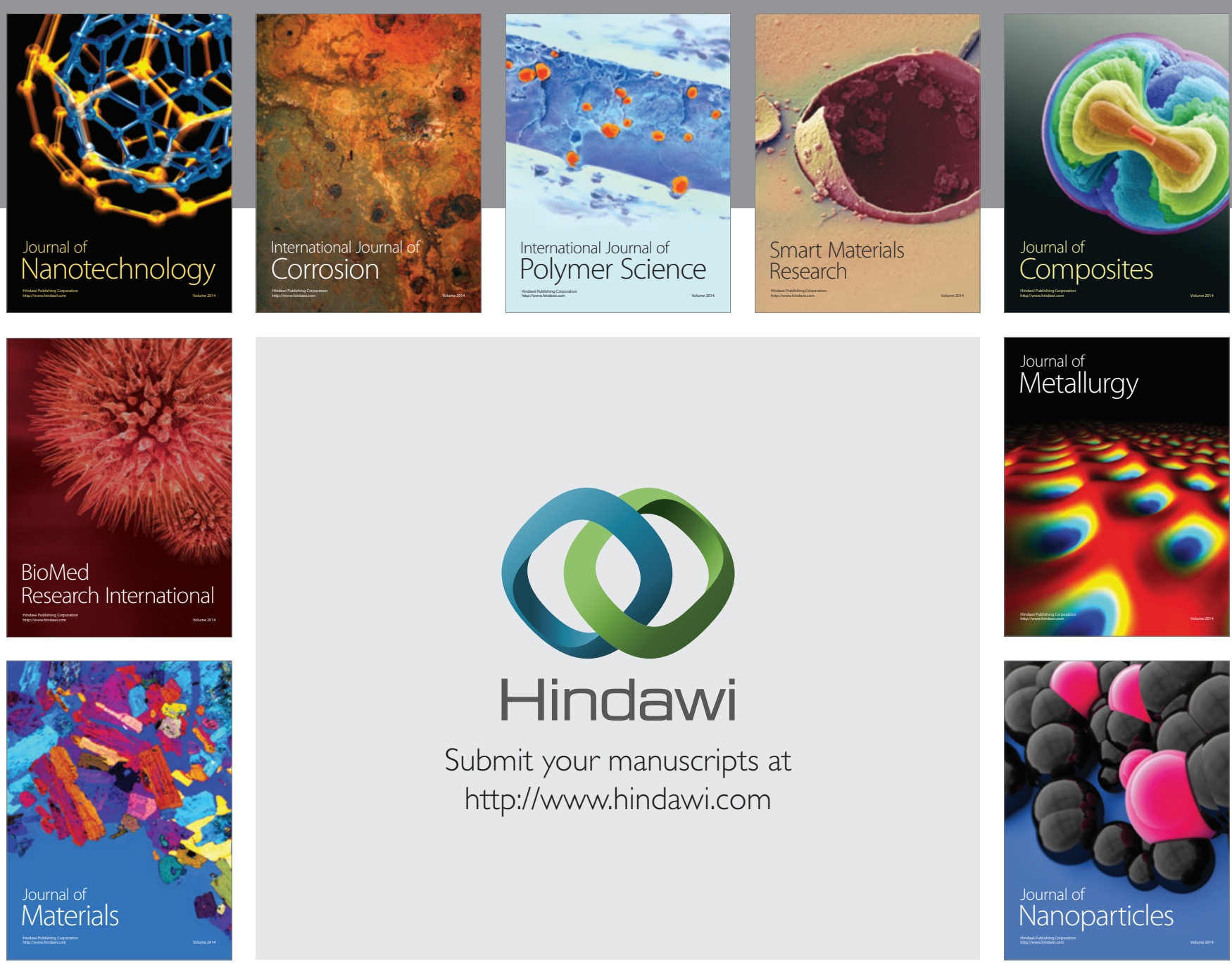

Submit your manuscripts at http://www.hindawi.com
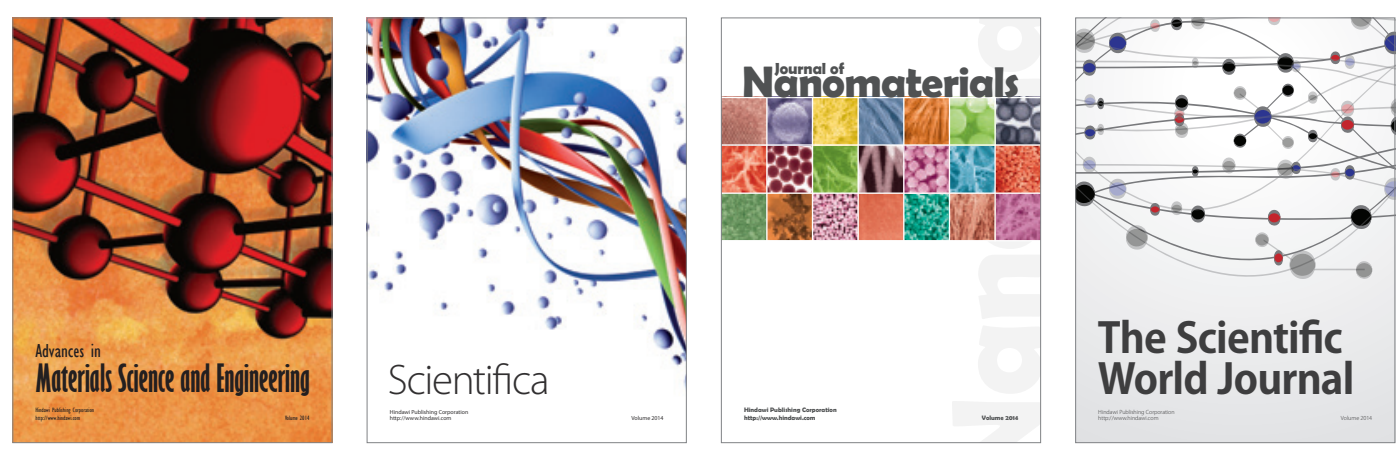

\section{The Scientific World Journal}
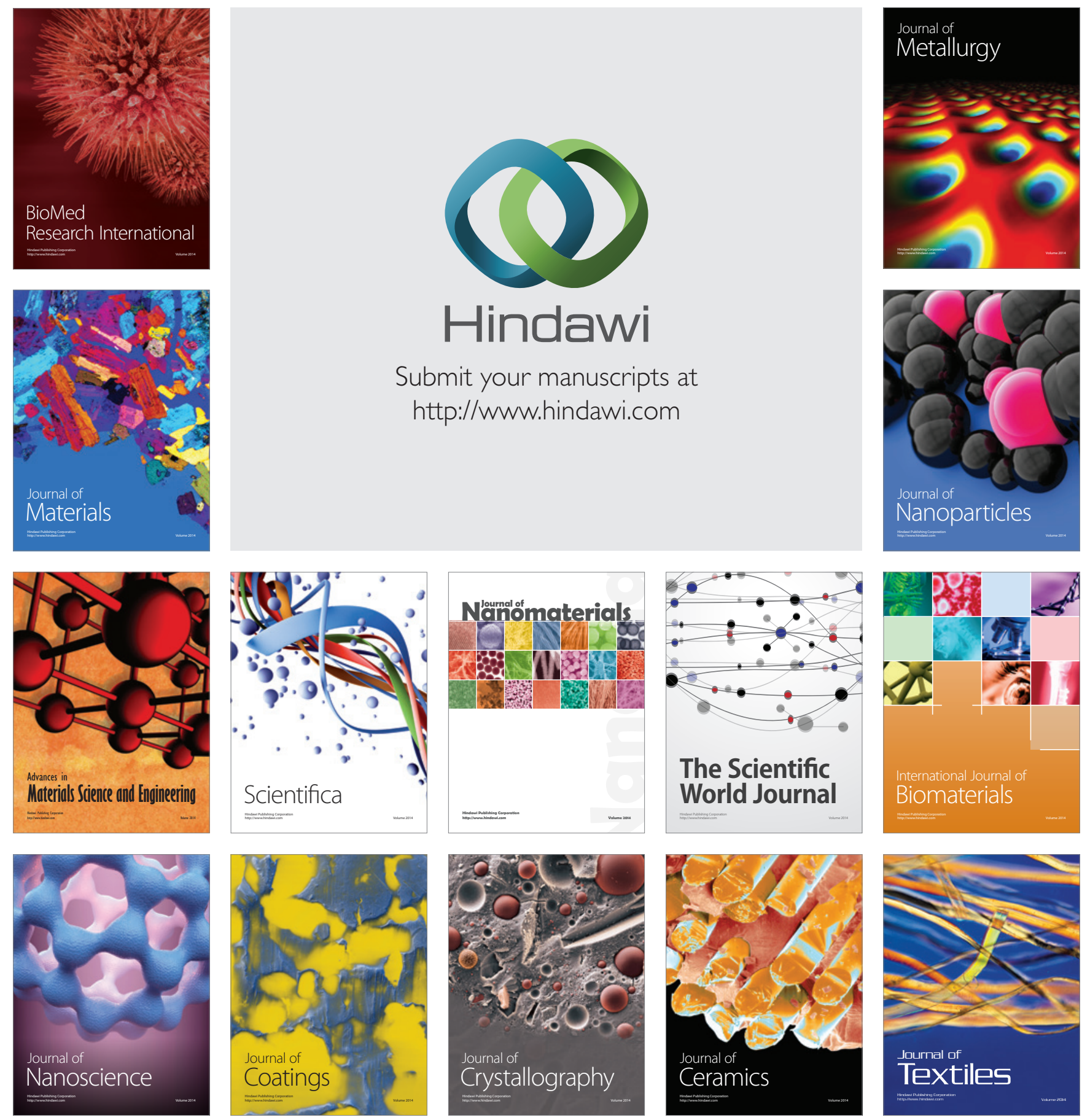